\title{
Single nucleotide variants in immune- response genes and the tumor microenvironment composition predict progression of mantle cell lymphoma
}

Guilherme Rossi Assis-Mendonça ${ }^{1 *}$ (D), André Fattori ${ }^{2}$, Rafael Malagoli Rocha ${ }^{3}$, Gustavo Jacob Lourenço ${ }^{4}$, Márcia Torresan Delamain ${ }^{5}$, Suely Nonogaki ${ }^{6}$, Vladmir Cláudio Cordeiro de Lima ${ }^{7}$, Gisele Wally Braga Colleoni ${ }^{8}$, Cármino Antonio de Souza ${ }^{2,5}$, Fernando Augusto Soares ${ }^{9}$, Carmen Silvia Passos Lima ${ }^{2,4}$ and José Vassallo ${ }^{1,9,10}$

\begin{abstract}
Background: There is evidence to consider that the tumor microenvironment (TME) composition associates with antitumor immune response, and may predict the outcome of various non-Hodgkin lymphoma subtypes. However, in the case of mantle cell lymphoma (MCL), a rare and aggressive disease, there is lacking a detailed study of the TME components, as well as an integrative approach among them in patients' samples. Also, from the genetic point of view, it is known that single nucleotide variants (SNVs) in immune-response genes are among important regulators of immunity. At present, it is uncertain whether SNVs in candidate immune-response genes and the TME composition are able to alter the prognosis in MCL.

Methods: We assessed a detailed TME composition in $88 \mathrm{MCL}$ biopsies using immunohistochemistry, which was automatically analyzed by pixel counting (Aperio system). We also genotyped SNVs located in candidate immuneresponse genes (IL12A, IL2, IL10, TGFB1, TGFBR1, TGFBR2, IL17A, IL17F) in $95 \mathrm{MCL}$ patients. We tested whether the SNVs could modulate the respective protein expression and TME composition in the tumor compartment. Finally, we proposed survival models in rituximab-treated patients, considering immunohistochemical and SNV models.

Results: High FOXP3/CD3 ratios ( $p=0.001)$, high IL17A levels $(p=0.003)$ and low IL2 levels $(p=0.03)$ were individual immunohistochemical predictors of poorer survival. A principal component, comprising high quantities of macrophages and high Ki-67 index, also worsened outcome $(p=0.02)$. In the SNV model, the CC haplotype of IL10 $(p<0.01)$, the GG genotype of IL2 rs2069762 ( $p=0.02)$ and the AA+AG genotypes of TGFBR2 rs3087465 ( $p<0.01)$ were independent predictors of outcome. Finally, the GG genotype of TGFB1 rs6957 associated with lower tumor TGF $\beta$ levels $(p=0.03$ ) and less CD163+ macrophages $(p=0.01)$, but did not modulate patients' survival.

Conclusions: Our results indicate that the TME composition has relevant biological roles in MCL. In this setting, immunohistochemical detection of T-reg cells, IL17A and IL2, coupled with SNV genotyping in IL10, TGFBR2 and IL2, may represent novel prognostic factors in this disease, following future validations.
\end{abstract}

Keywords: Mantle cell lymphoma, Tumor microenvironment, SNVs, Immunohistochemistry, Prognostic factors

\footnotetext{
* Correspondence: guilhermeram13@yahoo.com.br

'Department of Pathology, Faculty of Medical Sciences, University of

Campinas, Distrito de Barão Geraldo, Campinas, SP, Brazil

Full list of author information is available at the end of the article
}

(c) The Author(s). 2021, corrected publication 2021. Open Access This article is licensed under a Creative Commons Attribution 4.0 International License, which permits use, sharing, adaptation, distribution and reproduction in any medium or format, as long as you give appropriate credit to the original author(s) and the source, provide a link to the Creative Commons licence, and indicate if changes were made. The images or other third party material in this article are included in the article's Creative Commons licence, unless indicated otherwise in a credit line to the material. If material is not included in the article's Creative Commons licence and your intended use is not permitted by statutory regulation or exceeds the permitted use, you will need to obtain permission directly from the copyright holder. To view a copy of this licence, visit http://creativecommons.org/ licenses/by/4.0/. The Creative Commons Public Domain Dedication waiver (http://creativecommons.org/publicdomain/zero/1. 0/) applies to the data made available in this article, unless otherwise stated in a credit line to the data. 


\section{Background}

Mantle cell lymphoma (MCL) is an uncommon nonHodgkin lymphoma (NHL) subtype, marked by presence of the $\mathrm{t}(11: 14)$ translocation in more than $90 \%$ of the cases, which leads to overexpression of cyclin D1 [1]. MCL has an aggressive clinical course, debilitating potential and yet limited prognostic stratification. Some features are already known to impact MCL survival, such as the use of rituximab (anti-CD20 antibody) and the Mantle Cell Lymphoma International Prognostic Index (MIPI). The Ki-67 cell proliferation index, assessable in patients' biopsies, is also proposed as directly related to tumor aggressiveness [2]. More recently, molecular events, such as B-cell receptor activation and TP53 / $C D K N 2 A$ mutations, were associated with treatment resistance $[3,4]$. These results brought new insights in the pathophysiology of MCL. However, factors such as the interactions between tumor cells and surrounding inflammatory populations need further exploration.

In this setting, the composition of tumor microenvironment (TME) has emerged as a promising prognostic marker in patients with a variety of tumors, including NHLs [5]. The TME encompasses extracellular matrix, inflammatory cells, fibroblasts, the vascular bed and soluble signaling molecules. Interactions among these components control oxygen and nutrient supplies for tumor cells, and also regulate the antineoplastic immune response [5]. Depending on the balance among TME components, disease course may be defined either as immune evasion and tumor progression, or as an efficient immune response and disease clearance [6]. Assessment of the TME cellular composition has helped to better stratify prognosis in various types of NHLs [5]. For MCL, the roles of circulating monocytes [7], T-cells [8] and follicular dendritic cells [9] on patients' outcome have been demonstrated in few studies, but the remaining inflammatory cells, as well as an integrative approach among them, remain largely unexplored in this disease. Moreover, inflammatory cytokines, which compose the molecular counterpart of the TME, are also increasing subjects of interest in lymphoma, due to their capacity of modulating immune responses and lymphoma cells' growth [10-13]. For instance, one recent study characterized, in vitro, the role of IL10 in maintaining survival of MCL cells via M2-macrophages [13]. These findings not only highlighted important interplays among MCL cells, TME cells and cytokines, but also stressed the need of exploring cellular and molecular parameters of the TME in patient-derived samples.

However, as the capacity of immune response is variable in humans [14], it may be relevant to assess not only the levels of cytokine profiles, but also the genetic determinants for their expression. Previous studies demonstrated that single nucleotide variants (SNVs) located in immune-response genes, including cytokines, may alter NHL onset and progression [14-17]. This may be especially valid in the case of functional variants, in which alteration of the transcript and/or protein may regulate the tumor microenvironment composition and ultimately modulate disease outcome [18]. However, this question was not yet properly addressed in MCL, despite the role of immune subsets in sustaining the survival of lymphoma cells $[11,13,19]$.

Herein, we assessed the prognostic role of immuneresponse components of the TME in biopsies from a retrospective cohort of MCL. We also studied SNVs in immune-response related genes, attempting to elucidate whether they could alter the TME composition and the outcome of MCL patients.

\section{Methods}

\section{Patient selection and clinical data}

We analyzed all 122 MCL cases diagnosed between 1999 and 2016 at the Hematology and Hemotherapy Center of the University of Campinas $(n=74)$ and A. C. Camargo Cancer Center $(n=48)$.

The diagnosis of MCL was made according to the World Health Organization (WHO) Classification for Lymphoid Tumors [20]. Tumor cells were characterized by a CD20+/CD5+/cyclin D1+ phenotype. The Mantle Cell International Prognostic Index (MIPI) was calculated and used as the reference prognostic instrument [2].

\section{Single genetic variants choice and genotyping}

The choice of SNVs was based on a candidate gene approach. We selected SNVs in genes related to immuneresponse with previous evidences of active roles in lymphoma, cancer or modulation of the immune response [13-16, 21-42]. A minor allele frequency (MAF) of $5 \%$ was preconized. Sixteen SNVs were finally selected in 8 candidate genes: IL12A, IL2, IL10, TGFB1, TGFBR1, TGFBR2, IL17A and IL17F (Table 1).

DNA samples were extracted from peripheral blood of patients, using precipitation with lithium chloride. Assessments of DNA yield $(\mathrm{ng} / \mu \mathrm{L})$ and purity $(260 / 280$ and 260/230 ratios) were performed using the NanoDrop spectrophotometer (ThermoFisher Scientific, Wilmington, DE, USA). Whenever necessary, sodium acetate $(3 \mathrm{M})$ was added to the extracted DNAs, followed by new ethanol precipitations, to improve purity. The final concentration of all samples was set to $50 \mathrm{ng} / \mu \mathrm{L}$.

Genotyping of SNVs was performed using the Taqman $^{\oplus}$ OpenArray $^{\circ}$ QuantStudio $^{\mathrm{Tm}}$ Real-Time PCR System (Life Technologies Inc., Carlsbad, CA, USA). Briefly, DNA samples were pipetted together with Taqman ${ }^{\circ}$ Openarray $^{\circ}$ Master Mix on 384-well plates. This mixture was then transferred to genotyping plates using the 
Table 1 Genes, single nucleotide variants and their biological rationale for inclusion in this study

\begin{tabular}{|c|c|c|}
\hline Gene & SNVs & Biological rationale \\
\hline IL12A & rs755004, rs485497, rs568408, rs583911 & $\begin{array}{l}\text {-Controversial molecule in B-cell lymphoma models (antitumoral effect / } \\
\text { exhaustive effect in T-cells) [21, 22]; } \\
\text {-SNVs previously associated with lymphoproliferative disorders [16, 23-25]. }\end{array}$ \\
\hline IL2 & rs2069762, rs6822844 & $\begin{array}{l}\text {-Cytokine with potential cytotoxic effect in mantle cell lymphoma [26]; } \\
\text {-SNVs previously associated with the regulation of IL2 levels and lymphoma } \\
\text { prognosis }[15,27] .\end{array}$ \\
\hline IL10 & rs3024491, rs1800872, rs 1800890 & $\begin{array}{l}\text {-Cytokine with effects on mantle cell lymphoma proliferation and survival [13, 28]; } \\
\text {-SNVs were previously implicated on regulation of IL10 levels and } \\
\text { lymphomagenesis [14, 29-31]. }\end{array}$ \\
\hline TGFB1 & rs6957, rs1800471, rs1800469 & $\begin{array}{l}\text {-Pathway with a potential role in mantle cell lymphoma signaling [32]; } \\
\text {-SNVs associated with functional changes in the TGF } \beta \text { pathway [33-35]. }\end{array}$ \\
\hline TGFBR1 & rs334348 & $\begin{array}{l}\text {-Pathway with a potential role in mantle cell lymphoma signaling [32]; } \\
\text {-SNV with an effect on cancer risk and postulated functional change [36]. }\end{array}$ \\
\hline TGFBR2 & rs3087465 & $\begin{array}{l}\text {-Pathway with a potential role in mantle cell lymphoma signaling [32]; } \\
\text {-SNV associated with changes in promoter activity [37]. }\end{array}$ \\
\hline IL17A & rs3748067 & $\begin{array}{l}\text {-Molecule with potential but still uncertain role in B-cell lymphomas' pathophysiology, } \\
\text { including mantle cell lymphoma }[38,39] \text {; } \\
\text {-SNV previously associated with prognostic features in cancer, and with a putative } \\
\text { functional role [40]. }\end{array}$ \\
\hline IL17F & rs763780 & $\begin{array}{l}\text {-Molecule with a potential role in B-cell lymphomas, and adverse prognostic role in } \\
\text { T-cell lymphoma }[38,39,41] \text {; } \\
\text {-SNV previously associated with alterations in protein function [42]. }\end{array}$ \\
\hline
\end{tabular}

SNVs Single nucleotide variants

Openarray $^{\ominus}$ Accufill $^{\text {TM }}$ system. Thermocycling was performed during 40 cycles, and visualization of polymorphic alleles was possible by using fluorophores $\left(\mathrm{VIC}^{\mathrm{TM}}\right.$ and $\left.\mathrm{FAM}^{\mathrm{TM}}\right)$. A single reaction allowed the simultaneous detection of all 16 SNVs.

\section{Tissue samples and immunohistochemistry}

Formalin-fixed, paraffin embedded (FFPE) diagnostic blocks from MCL cases were obtained from the participating hospitals. All slides were reviewed by an experienced hematopathologist (JV), and two representative areas from each source block were selected to construct a tissue microarray (TMA). Core fragments with diameter of $1 \mathrm{~mm}$ were taken using a Tissue Microarrayer (Beecher Instruments, Silver Springs, MD), and samples were put as duplicates in the recipient block. Immunohistochemistry was then performed, using a broad panel of antibodies to study key TME components, including tumor-infiltrating lymphocytes (CD3, CD4, PD1, FOXP3, CD8, granzyme B, perforin, CD57) and macrophages (CD68, CD163, iNOS). We also performed immunohistochemistry to detect the proteins encoded by the genes used in the SNV approach (IL12A, IL2, IL10, TGF $\beta$, TGFBR1, TGFBR2, IL17A, IL17F). Reactions for Ki-67 and SOX11 were performed as well. A detailed list of antibodies, including suppliers and dilutions, is in supplementary Table 1.

Eighty-nine blocks were used for SOX11 evaluation, and 88 were considered suitable for TME assessment.
The immunohistochemical (IHC) reaction was performed using standard procedures. Briefly, unstained slides were submitted to antigen retrieval using citric acid solution/pH 6.0 or EDTA/pH 9.0 buffers. Endogenous peroxidase activity was blocked by hydrogen peroxide solution for $20 \mathrm{~min}$. Exposure to the primary antibody was performed overnight. The signal was amplified by a third generation polymer tagged with antimouse/anti-rabbit immunoglobulins and horseradish peroxidase (Novolink Polymer Detection System, Leica Biosystems, Newcastle Upon Tyne, UK), and the color was developed with diaminobenzidine chromogenic substrate (Sigma, D5637, St. Louis, MO, USA). Positive cells were observed in golden brown color. The negative control was performed by omitting the primary antibody.

\section{Immunohistochemical analysis}

Quantification of IHC markers was performed on the entire TMA cores. For the majority of the markers, this was done automatically using the Aperio ImageScope ${ }^{\text {TM }}$ software (Leica Microsystems Inc., Buffalo Grove, IL, USA) (Fig. 1). The Positive Pixel Count algorithm was used to grade pixels as negative, low positive, positive and high positive. Inputs for the algorithm were a hue value of 0.1 , hue width of 0.5 and color saturation threshold of 0.1 (for most cores). In some rare cases presenting with nonspecific background, the color saturation threshold was increased to 0.15 to minimize noise capture. For antibodies staining specific TME populations (e.g. CD68, FOXP3, CD3), the fraction of all 


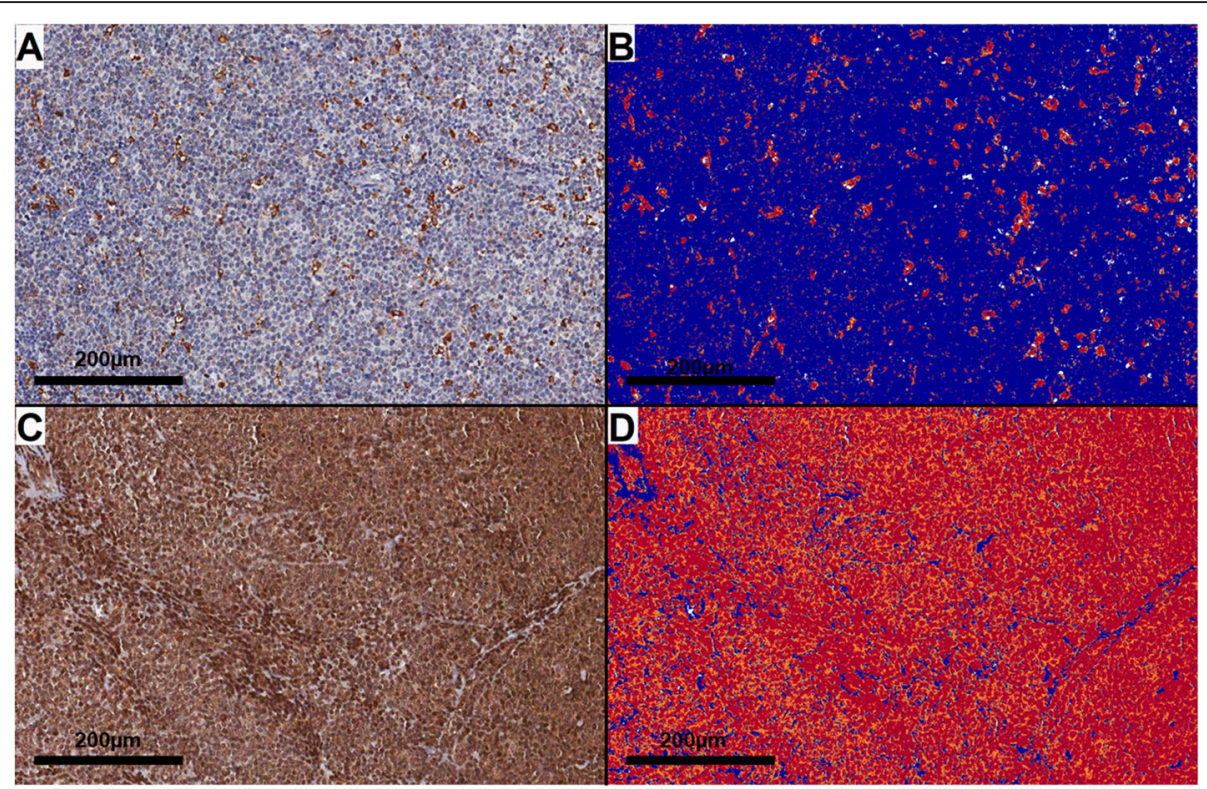

Fig. 1 Representative examples of immunohistochemical analysis using the Aperio system in mantle cell lymphoma. Assessment of CD68 (a-b) and ILI7A (c-d), in which "a" and "c $\mathbf{c}$ " illustrate the original stainings, and "b" and "d", the respective decodified images. In the latter ones, blue color identifies negative pixels, yellow color indicates weak positive staining, orange color highlights positive staining and red color denotes strong positive staining

positive pixels was considered as the score. For antibodies that heterogeneously stained both tumor and microenvironment cells (e.g. cytokine antibodies), we calculated the $\mathrm{H}$-score, which applies different multipliers for low positive, positive and high positive stainings (1, 2 and 3 , respectively) [43].

For SOX11 assessment, we performed categorization using a visual approach, similarly to others [44, 45]. In this setting, cases were classified as SOX11 ${ }^{\text {high }}$ (nuclear staining in more than $10 \%$ of cells) or SOX $11^{\text {low }}$ (nuclear staining in less than $10 \%$ of cells or negative staining).

Immunohistochemical scores were analyzed individually and also as part of a dimension-reducing methodology (principal component analysis; please see "statistical analyses").

\section{Statistical analyses}

Associations between variables were assessed using $\chi^{2}$, Fisher's exact test, Mann Whitney's test and Spearman's correlation index. When necessary, continuous variables were dichotomized as "high" and "low" based on the median values.

Regarding SNVs assessment, the Hardy-Weinberg equilibrium (HWE) was evaluated using the chi-square (x2) goodness-of-fit test. Pairwise linkage disequilibrium (LD) analyses were performed using the Haploview 4.2 software (www.broad.mit.edu/mpg/ haploview) to ensure that the markers were appropriate for inclusion in the haplotype estimates. The LD was measured by the disequilibrium coefficient ( $\left.D^{\prime}\right)$, and LD significance was considered at a $\mathrm{D}^{\prime} \geq 80 \%$.

Exploratory principal component analysis (PCA) with Varimax rotation was used as a dimension-reducing method in IHC quantifications. Interactions between IHC variables were estimated and expressed as principal components. In this setting, stronger interactions had higher computed variance values [46]. The associations between principal components and clinicopathological features were estimated with linear regression analyses.

Survival analyses were also performed. However, as antiCD20 therapy may be a potential confounder for the TME function, only patients who received rituximab in first-line regimens were included in this analysis [47]. In a similar way, only patients that did not undergo bone marrow transplantation were put in survival analysis, as transplantation modulates the proportion of immune cells [48, 49]. Overall survival (OS) was defined as the time from diagnosis until death by any cause or last follow-up. Event-free survival (EFS) was defined as the time from diagnosis until death, disease progression or last follow-up. Three survival models were tested: one model considering individual IHC assessments (IHC model), another one testing genotyping data (SNV model), and one last model using the data from PCA. Survival curves were plotted with the Kaplan-Meier method, and compared using the log-rank test. We further performed Cox univariate regressions for variables influencing survival in Kaplan-Meier curves. Finally, a Cox multivariate model was proposed, enclosing all variables with a $p$ value of less than 0.10 in the univariate analysis. 
Simultaneous testing of redundant information (e.g. age and the MIPI) was not performed. Follow-up update was performed on January, 2019.

The significant results of multivariate Cox regressions were internally validated using the Bootstrap resampling method (1000 replications).

When necessary, the Benjamini-Hochberg method was performed for correction of multiple comparisons. All statistical tests were two-tailed, and a $p$ value of less than 0.05 was considered statistically significant.

\section{Results}

\section{Demographic and clinical characteristics of the population}

Median age at diagnosis for all MCL patients was of 66 years old (range: $31-93$ ), and there was a predominance of male sex $(93 / 122$ or $76.2 \%)$. The majority of patients $(107 / 122$ or $87.7 \%)$ were included in Ann Arbor stages III or IV. The MIPI allowed classification of available patients as high-risk disease (35.3\%), followed by intermediate risk (27.0\%) and, finally, low risk (24.6\%). Seventy-eight patients $(63.9 \%)$ had received rituximab as first-line therapy. Twenty-seven patients (22.1\%) underwent hematopoietic stem-cell transplantation (autologous in 26 cases and allogeneic in 1). The main clinical variables are detailed in supplementary Table 2.

\section{Immunohistochemical quantifications}

In 88/122 (72.1\%) cases, diagnostic FFPE blocks were suitable for TME assessment. The most frequent immune cells found on the MCL biopsies were T lymphocytes, mainly CD4+ (median $=6.43 \%$ of pixels, range: 0.09-58.60). Macrophages (CD68+) were slightly less frequent (median $=3.82 \%$ of pixels, range: $0.79-23.69$ ). Regarding inflammatory cytokines, IL17A had the highest expression (median HScore $=223.85$, range: $54.18-$ 281.40) (Fig. 2). The expression of TGFBR2 was visually negative in all cases, therefore, no quantification was performed. Representative stainings for each marker are available in supplementary Figs. 1, 2 and 3.

Positive correlations were found between some of the IHC markers: CD4 with CD8 $(p<0.001)$, perforin with CD8 $(p=0.02)$, and CD68 with CD4 ( $<<0.001)$, CD8 $(p=0.001)$, and IL10 ( $\mathrm{p}<0.001)$. IL17A and CD57 were inversely correlated ( $p=0.008)$ (Fig. 3 ).

Higher pixel counts of PD1+ cells were associated with less B-symptoms at diagnosis $(p=0.04)$. Also, higher levels of macrophages (CD68+) and higher CD4/CD8 ratios were found in patients with less aggressive MIPI categories (low or intermediate risks, $p=0.02$ and 0.04 , respectively). In contrast, higher $\mathrm{CD} 8 / \mathrm{CD} 3$ ratios were more frequently found on high-risk MIPI patients $(p=0.02)$. Finally, high IL12A and IL17A levels associated, respectively, with bone marrow infiltration $(p=0.01)$ and blastoid cytology ( $p=0.04)$ (supplementary Tables 3 and 4).

Regarding SOX11 evaluation, the majority of patients were categorized as SOX11 ${ }^{\text {high }}$ (76 out of 89 evaluable cases, or $85.4 \%)$. The remaining cases (13/89 or $14.6 \%)$ were classified as SOX11 ${ }^{\text {low }}$ (representative photomicrographs in supplementary Fig. 4). There was a higher percentage of female patients in the SOX11 ${ }^{\text {low }}$ group (46.2 vs 19.7\%; $p=0.03$ ); no other clinicopathological differences were seen (supplementary Table 5). Composition of the TME was mostly similar between SOX11 ${ }^{\text {high }}$ and SOX11low groups, except for a trend towards higher IL2 and perforin levels in SOX $11^{\text {low }}$ cases (supplementary Fig. 5).

\section{Single nucleotide variants genotyping and TME composition}

Genotyping of SNVs was possible in 95 patients. In all but 1 SNV (TGFBR1 rs334348) the HWE was observed (supplementary Table 6).

The only SNV associated with the respective protein levels was TGFB1 rs6957. Significantly lower TGF $\beta$
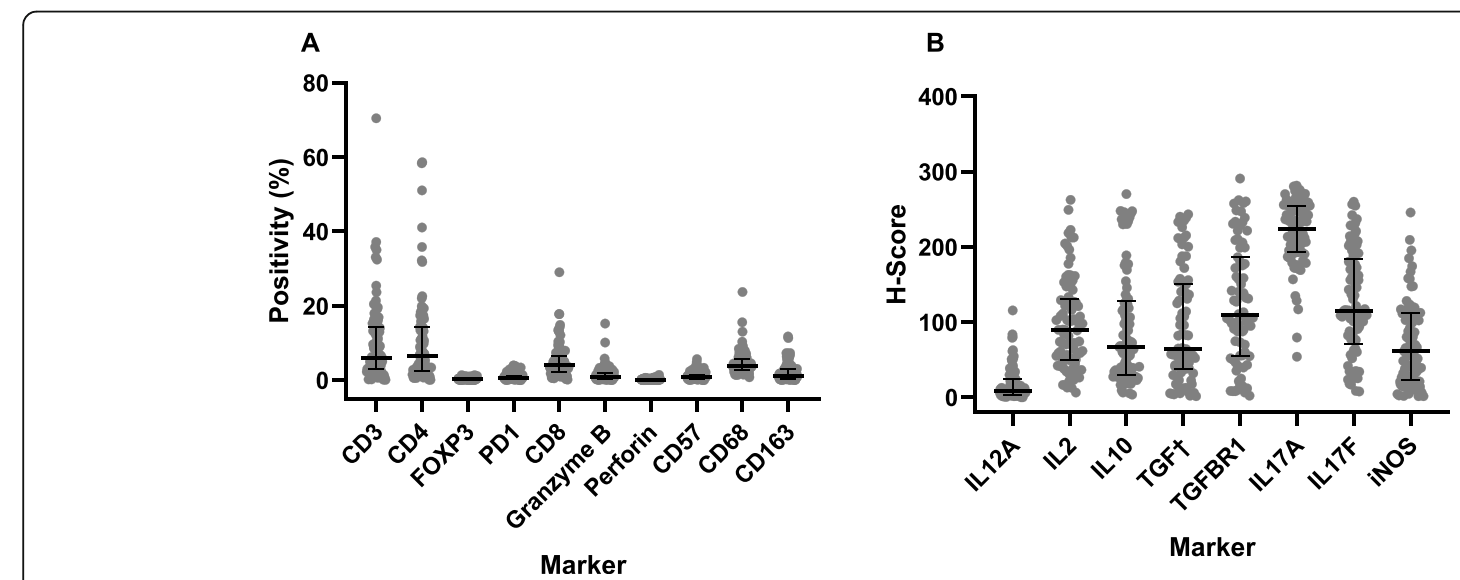

Fig. 2 Quantifications of the tumor microenvironment markers in mantle cell lymphoma. a Markers quantified using positivity levels (0-100\%) and (b) Markers quantified using the H-Score (0-300). Graphs show scatterplots with superimposed median levels and interquartile range 


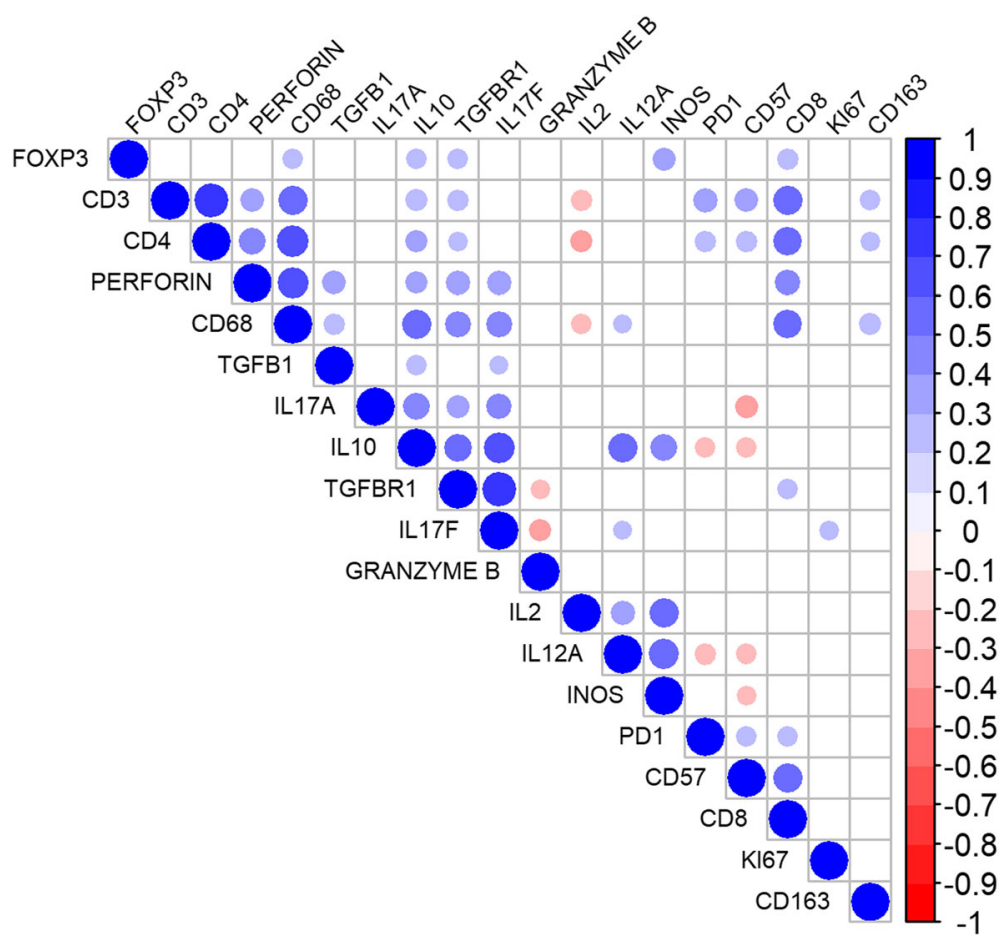

Fig. 3 Correlation matrix for immunohistochemical markers in mantle cell lymphoma. Blueish tones indicate higher positive correlations, whereas reddish tones point toward negative correlations. Larger circle diameters denote higher modules of the correlation coefficient (r). Non-significant correlations are shown as white intersections

levels were found in tumors from patients harboring the GG genotype $(p=0.03$, Fig. $4 \mathrm{a})$. The same genotype also associated with decreased $\mathrm{CD} 163+$ pixels ( $p=0.01$, Fig. $4 \mathrm{~b})$.

Besides, the recessive "T" allele of IL2 rs6822844 was seen in patients with increased FOXP3 pixel counts $(p=$ 0.001 , Fig. 4c). Finally, considering IL17F rs763780, patients carrying the recessive " $C$ " allele had tumors with lower quantities of perforin-expressing cells $(p<0.0001$, Fig. 4d).

Based on the LD coefficients, we were able to estimate haplotypes in IL12A and IL10 (supplementary Table 7, supplementary Fig. 6). The haplotypes presented no associations with features at diagnosis (data not shown).

\section{Survival models including individual}

\section{immunohistochemical markers and SNVs}

Survival analyses were performed in 55 patients that received rituximab and did not undergo stem cell transplantation. Univariate analyses considering clinical features evidenced significant adverse prognostic roles of Bsymptoms (both in EFS and OS), bone marrow infiltration (OS only) and MIPI index (trend of significance in EFS only (supplementary Table 8). These variables were, therefore, used as covariates on multivariate Cox regressions.

Univariate survival analyses of IHC markers showed that the presence of low IL2 levels associated with worse
EFS and marginally with OS ( $p=0.01$ and 0.09 , respectively) (Fig. 5a and Fig. 6a). High FOXP3/CD3 ratios ( $p=$ $0.002)$ and high $\mathrm{CD} 8 / \mathrm{CD} 3$ ratios $(p=0.03)$ associated only with worse EFS, and low granzyme B levels presented a trend of association with worse EFS $(p=0.06)$ (Figs. 5b-d). On the other hand, high IL17A levels associated only with shorter OS ( $p=0.03$ ) (Fig. 6b). SOX11 expression was not associated either with EFS or with OS (Figs. 5e and Fig. 6c).

Regarding the SNVs, presence of the GG genotype of IL2 rs2069762 negatively affected both EFS ( $p=0.01$, Fig. 5f) and OS ( $p=0.006$, Fig. $6 \mathrm{~d})$. In addition, patients carrying the CC haplotype in IL10, involving rs3024491 and rs1800872, had improved EFS ( $p=0.04$, Fig. 5g) and OS ( $p=0.007$, Fig. 6e). Besides, the GG genotype of TGFB1 rs6957, compared with GA + AA genotypes, associated solely with worse OS ( $p=0.03$, Fig. $6 \mathrm{f})$. Finally, the AA+AG genotypes of TGFBR2 rs3087465 $(p=0.001)$ and the TC + CC genotypes of IL17F rs763780 ( $p=0.03)$ associated only with worse EFS (Fig. 5 h and i).

After multivariate analyses, in the IHC model, high FOXP3/CD3 ratios (HR $=5.03,95 \%$ CI: $1.97-12.84, p=$ $0.001)$ and low IL2 tumor levels $(\mathrm{HR}=2.83,95 \% \mathrm{CI}$ : $1.06-7.58, p=0.03$ ) remained independent predictors of worse EFS, whereas high IL17A tumor levels were independently associated with worse $\mathrm{OS}(\mathrm{HR}=4.68,95 \% \mathrm{CI}$ : 1.72-12.77, $p=0.003$ ) (Table 2). 

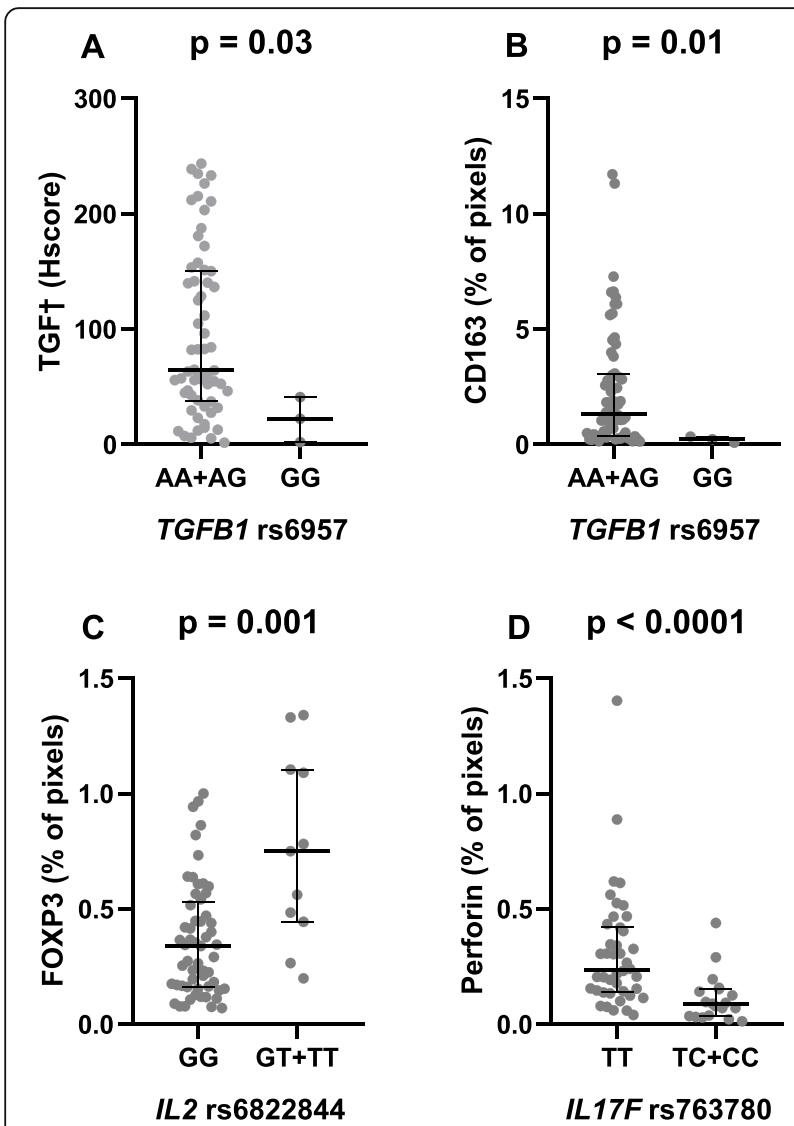

Fig. 4 Modulation of the tumor microenvironment in mantle cell lymphoma by single nucleotide variants. Associations of TGFB1 rs6957 with (a) TGF $\beta$ and (b) CD163 levels. c Association of IL2 rs6822844 with FOXP3 levels; (d) Association of IL17F rs763780 with perforin levels. Graphs show scatterplots with superimposed median levels and interquartile range. All $p$-values were obtained with twotailed Mann-Whitney tests

In the multivariate SNV model, presence of the CC haplotype in IL1O was independently associated both with prolonged EFS ( $\mathrm{HR}=0.32$, 95\% CI: $0.14-0.74, p=0.008$ ) and prolonged $\mathrm{OS}(\mathrm{HR}=0.26,95 \% \mathrm{CI}: 0.10-0.68, p=$ 0.006). In addition, the GG genotype of IL2 rs2069762 remained an independent predictor of EFS $(\mathrm{HR}=3.13$, 95\% CI: $1.12-8.69, p=0.02)$. Finally, the AA+AG genotypes of TGFBR2 rs3087465 were associated with worse EFS $(\mathrm{HR}=4.32,95 \% \mathrm{CI}: 1.88-9.93, p=0.001)$.

\section{Principal component analysis}

To address the interplay among TME components with a more biologically plausible approach, we used PCA to verify interactions and trends of convergence among the various IHC markers. The final PCA model was based on 6 factors and explained $75.02 \%$ of the variance (supplementary Table 9). The first component highlighted the opposition between granzyme B and IL10, IL17A, IL17F and TGFBR1. The second one directly associated
FOXP3/CD3 and CD8/CD3 ratios and opposed them against macrophage infiltration (CD68). The third component emphasized the presence of a cytotoxic marker (CD57) that opposed IL17A and the proliferative index $\mathrm{Ki}-67$. On the fourth component, pan-macrophages (CD68+), M2-macrophages (CD163+) and Ki-67 were directly associated. The fifth component aggregated together two cytotoxic markers (granzyme B and perforin), as well as IL2 levels. Finally, the last component inversely associated T-cell levels and IL2.

The presence of the fourth principal component was associated with blastoid cytology, using a linear regression model $\left(F=9.43, p=0.003, R^{2}=0.14\right)$. No other associations with features at diagnosis were seen.

The third and fourth principal components presented associations with $\mathrm{OS}$ in univariate analysis $(p=0.08$ and 0.03 , respectively). After multivariate analysis, only the presence of the fourth component was significantly associated with worse OS (HR $=1.68,95 \% \mathrm{CI}: 1.08-2.62, p=$ 0.02) (Table 2).

\section{Discussion}

In this cohort of MCL patients, the traditional assessment of TME components in tumor biopsies was complemented with the genotyping of candidate SNVs from immune-response genes. Increased numbers of FOXP3+ lymphocytes, higher IL17A, lower IL2 and a principal component involving Ki67 and macrophages were independently associated with worse outcome in the tumor compartment. Within the genetic counterpart of the TME, SNVs in IL10, TGFBR2 and IL2 also showed association with prognosis. Our results, although exploratory, provide further evidence that the immune microenvironment poses relevant biological relevance in this disease. This, ultimately, could foster the development of TME-directed therapies that may complement the traditional treatment $[1,13,50,51]$.

The prognostic role of some T-cell subpopulations in MCL was previously assessed by Nygren et al. (2014), who found that the predominance of CD4+ lymphocytes over CD8+ lymphocytes was associated with less aggressive disease [8]. As CD4+ cells represent a heterogeneous group of lymphoid subpopulations, it remains to be elucidated how the balance among different subtypes of CD4+ lymphocytes could explain their findings. We assessed some of these subtypes and found that high FOXP3/CD3 ratios and high IL17A tumor levels were associated with worse outcomes. FOXP3 is traditionally used as a marker of CD4+ regulatory T-cells (T-reg), which were already implicated on immune suppression and worse prognosis of other lymphoma subtypes, such as follicular lymphoma [52]. Complementarily, IL17A is produced by other subtypes of T-CD4+ cells (Th17 cells). It enhances proliferative and pro-angiogenic 

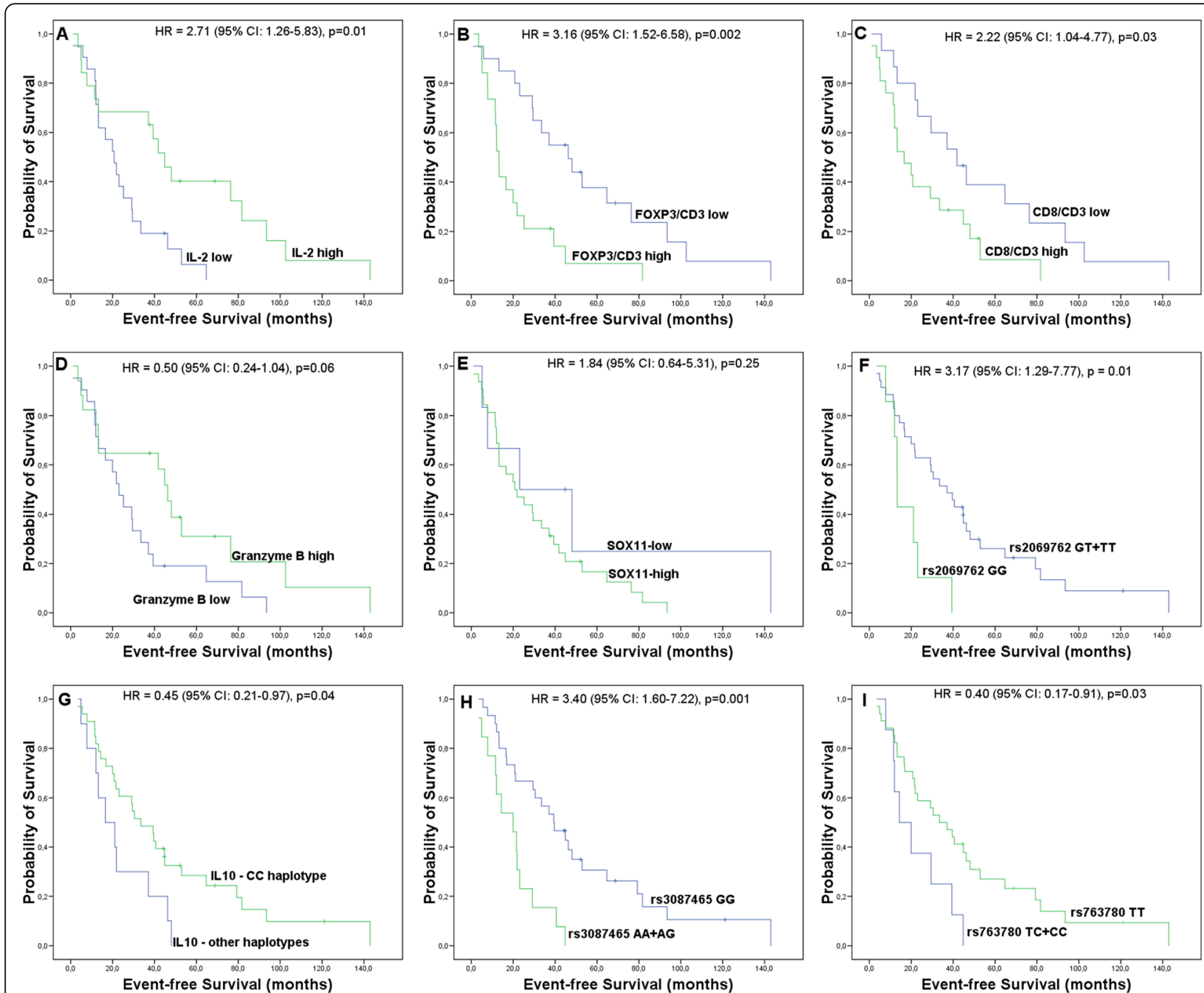

Fig. 5 Kaplan-Meier curves (event-free survival) of mantle cell lymphoma patients. Categorizations by (a) IL2 levels, (b) FOXP3/CD3 ratios, (c) CD8/ CD3 ratios, (d) Granzyme B levels, (e) SOX11 positivity, (f) Genotypes of IL2 rs2069762, (g) Haplotypes in IL10, (h) Genotypes of TGFBR2 rs3087465 and (i) Genotypes of IL17F rs763780. Each graphic contains the hazard ratios and p-values obtained in the respective univariate Cox regressions

signals to neoplastic cells, including lymphoma cell lines, which might explain the adverse prognostic role found in our study $[53,54]$. Interestingly, the fact that both Treg cells and IL17A were prognostic in our series also raises the possibility of involvement of "inflammatory $\mathrm{T}$ regs" (IL17 producing T-reg cells) on the immune landscape of MCL [55]. Confirmation of this hypothesis relies on additional studies performing experiments such as double immunostainings.

When evaluating the TME by PCA, tumors rich in CD163 and with a high proliferative index had a worse prognosis. An association with the blastoid cytomorphology was also observed. The presence of higher Ki-67 is a known prognostic factor in MCL [2], and a higher density of CD163+ macrophages was previously associated with adverse clinical features in this disease [7]. Recently, an interplay between M2-macrophages and MCL cells was also described as relevant for the production of CSF1 and survival of lymphoma cells [13], which might explain the adverse prognostic role of the PCA detected in the present study.

Regarding the genetic counterpart of the TME, we found that the CC haplotype in IL10 (composed of the "C" alleles of rs3024491 and rs1800872) was a predictor of better OS and EFS in MCL. In previous reports addressing patients with Hodgkin's lymphoma and B-cell lymphomas, similar results were achieved for the second SNV individually $[56,57]$. It was already suggested that the locus involving rs1800872 might modulate IL10 production, however, the results concerning this modulation are conflicting [56]. On the other hand, Assis et al. [29] reported that the "A" allele of rs3024491 associated with higher production of IL10 than the " $\mathrm{C}$ " allele, a finding that might have an impact on the CC haplotype. In our 

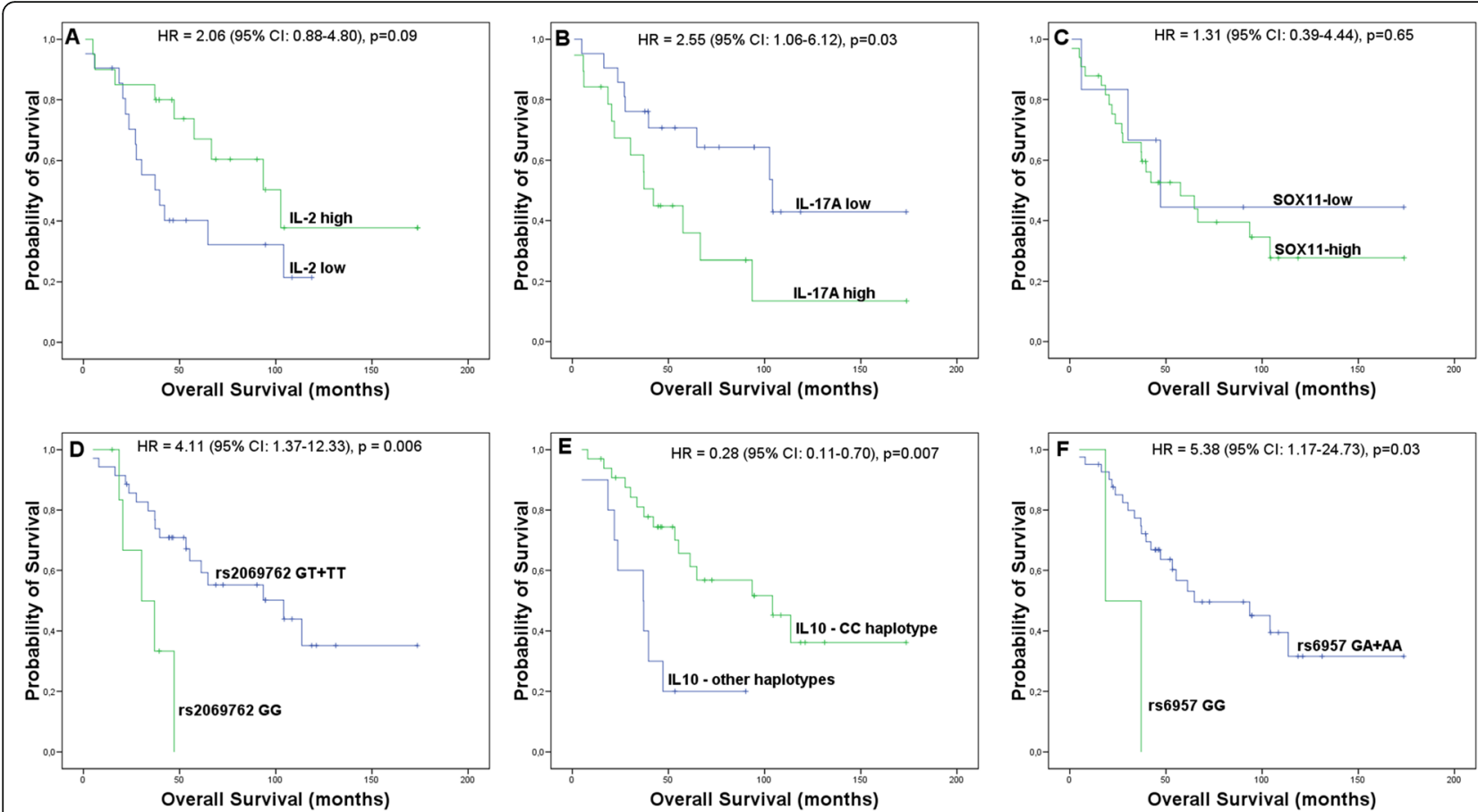

Fig. 6 Kaplan-Meier curves (overall survival) of mantle cell lymphoma patients. Categorizations by (a) IL2 levels, (b) IL17A levels, (c) SOX11 positivity, (d) Genotypes of IL2 rs2069762, (e) Haplotypes in IL10 and (f) Genotypes of TGFB1 rs6957. Each graphic contains the hazard ratios and $\mathrm{p}$-values obtained in the respective univariate Cox regressions

samples, we did not find any evidence of changes in local IL10 production either by the SNVs or by the CC haplotype; however, the systemic levels of this interleukin need to be addressed in further studies. A reduction of IL10 production by the haplotype seems a plausible explanation for the prolonged survival of CC patients, because IL10 induces a pro-tumorigenic microenvironment in MCL [13].

Another potentially targetable pathway in MCL is TGF $\beta$ and related proteins. Rizzatti et al. (2005) described that several genes from the TGFB superfamily were up-regulated in MCL samples, compared to controls, but this was little explored in further studies [32]. In our cohort, we found that the $\mathrm{AA}+\mathrm{AG}$ genotypes of TGFBR2 rs3087465 independently associated with poorer EFS. To the best of our knowledge, this is the first association of this SNV with survival in cancer patients. The" A" allele of rs3087465 was previously found to increase the promoter activity of TGFBR2 [37], but its specific role in MCL and the mechanisms influencing survival in our cohort are yet to be elucidated. In the same pathway, the SNV TGFB1 rs6957 was not a predictor of outcome after multivariate analysis; however, the GG genotype was associated with decreased levels of TGF $\beta$ and CD163+ macrophages in MCL biopsies. These findings are similar to a previous report in asthma patients, in whom this SNV also modulated macrophage proliferation [33]. However, the low frequency of the
GG genotype of rs6957 demands further investigation in larger sample sizes.

Finally, considering the cytotoxic (Th1) immuneresponse pathway, we found that the GG genotype of IL2 rs2069762 was an independent predictor of worse EFS. This mirrors the findings of Cerhan et al. (2007), in which the same genotype worsened the survival of follicular lymphoma patients in the pre-rituximab era [15]. Interestingly, the GG genotype was previously associated with reduction of IL2 production in healthy individuals [58]. Even though the SNV was not associated with modulation of IL2 levels in our samples, the presence of low scores of IL2, in the IHC model, was associated with worse EFS. Taken together, these results endorse the role of IL2-dependent cytotoxicity observed in MCL experimental models [26]. Therefore, further investigation of this pathway in patient-derived samples should be fostered.

In our cohort of MCL, SOX11 expression was not associated with prognosis. The importance of this transcription factor for the diagnosis of MCL is already established [59]. More recently, the role of this molecule in MCL homing and migration was also proposed [60]. However, a possible prognostic role remains in debate. This is illustrated by controversial results associating SOX11 negativity with both better and worse clinical outcomes in this disease $[61,62]$. We believe that this controversy might be due to different approaches (gene 
Table 2 Univariate and multivariate Cox regressions for candidate biomarkers in mantle cell lymphoma survival

\begin{tabular}{|c|c|c|c|c|c|c|c|c|}
\hline \multirow[t]{2}{*}{ Biomarker } & \multicolumn{4}{|l|}{ Univariate } & \multicolumn{4}{|l|}{ Multivariate } \\
\hline & $\begin{array}{l}\text { EFS } \\
\text { HR }(95 \% \mathrm{Cl})\end{array}$ & $p$ & $\begin{array}{l}\text { OS } \\
\text { HR (95\% Cl) }\end{array}$ & $p$ & $\begin{array}{l}\text { EFS* } \\
\text { HR }(95 \% \text { Cl) }\end{array}$ & $p$ & $\begin{array}{l}\text { OS* }^{*} \\
\text { HR }(95 \% \mathrm{Cl})\end{array}$ & $p$ \\
\hline \multicolumn{9}{|c|}{ Immunohistochemical model } \\
\hline \multicolumn{9}{|c|}{ FOXP3/CD3 ratio } \\
\hline High & $3.16(1.52-6.58)$ & 0.002 & $1.77(0.75-4.19)$ & 0.18 & $5.03(1.97-12.84)$ & $0.001^{\mathrm{a}}$ & N/A & N/A \\
\hline Low & Reference & & Reference & & Reference & & Reference & \\
\hline \multicolumn{9}{|c|}{$\mathrm{CD} 8 / \mathrm{CD} 3$ ratio } \\
\hline High & $2.22(1.04-4.77)$ & 0.03 & $1.06(0.44-2.51)$ & 0.88 & $1.02(0.33-3.13)$ & 0.96 & N/A & N/A \\
\hline Low & Reference & & Reference & & Reference & & Reference & \\
\hline \multicolumn{9}{|l|}{ Granzyme B } \\
\hline High & $0.50(0.24-1.04)$ & 0.06 & $0.69(0.28-1.67)$ & 0.41 & $1.18(0.51-2.72)$ & 0.69 & N/A & N/A \\
\hline Low & Reference & & Reference & & Reference & & Reference & \\
\hline \multicolumn{9}{|l|}{ IL2 } \\
\hline High & Reference & 0.01 & Reference & & Reference & $0.03^{b}$ & Reference & 0.07 \\
\hline Low & $2.71(1.26-5.83)$ & & $2.06(0.88-4.80)$ & 0.09 & $2.83(1.06-7.58)$ & & $2.50(0.92-6.77)$ & \\
\hline \multicolumn{9}{|l|}{ IL17A } \\
\hline High & $1.48(0.73-2.97)$ & 0.27 & $2.55(1.06-6.12)$ & 0.03 & N/A & N/A & $4.68(1.72-12.77)$ & $0.003^{c}$ \\
\hline Low & Reference & & Reference & & Reference & & Reference & \\
\hline \multicolumn{9}{|l|}{$\underline{\text { SNV model }}$} \\
\hline \multicolumn{9}{|l|}{ IL2 rs2069762 } \\
\hline GG & $4.26(1.56-11.60)$ & 0.005 & $9.05(2.33-35.05)$ & 0.001 & $3.13(1.12-8.69)$ & $0.02^{d}$ & $2.73(0.86-8.67)$ & 0.08 \\
\hline $\mathrm{GT}+\mathrm{TT}$ & Reference & & Reference & & Reference & & Reference & \\
\hline \multicolumn{9}{|l|}{ TGFB1 rs6957 } \\
\hline GG & $1.86(0.43-7.92)$ & 0.39 & $5.38(1.17-24.73)$ & 0.03 & N/A & $\mathrm{N} / \mathrm{A}$ & $3.22(0.57-18.15)$ & 0.18 \\
\hline $\mathrm{GA}+\mathrm{AA}$ & Reference & & Reference & & Reference & & Reference & \\
\hline \multicolumn{9}{|c|}{ TGFBR2 rs3087465 } \\
\hline$A A+A G$ & $3.40(1.60-7.22)$ & 0.001 & $1.37(0.56-3.36)$ & 0.47 & $4.32(1.88-9.93)$ & $0.001^{\mathrm{e}}$ & N/A & N/A \\
\hline GG & Reference & & Reference & & Reference & & Reference & \\
\hline \multicolumn{9}{|c|}{ IL10 CC haplotype } \\
\hline Present & $0.45(0.21-0.97)$ & 0.04 & $0.28(0.11-0.70)$ & 0.007 & $0.32(0.14-0.74)$ & $0.008^{f}$ & $0.26(0.10-0.68)$ & $0.006^{9}$ \\
\hline Absent & Reference & & Reference & & Reference & & Reference & \\
\hline \multicolumn{9}{|c|}{ IL17F rs763780 } \\
\hline $\mathrm{TC}+\mathrm{CC}$ & $0.40(0.17-0.91)$ & 0.03 & $1.16(0.34-3.99)$ & 0.80 & $1.42(0.47-4.23)$ & 0.52 & N/A & N/A \\
\hline$\pi$ & Reference & & Reference & & Reference & & Reference & \\
\hline \multicolumn{9}{|c|}{ Principal components model } \\
\hline Component 3 & $0.670(0.40-1.10)$ & 0.12 & $0.58(0.31-1.08)$ & 0.08 & N/A & N/A & $0.77(0.48-1.24)$ & 0.29 \\
\hline Component 4 & $1.34(0.89-2.01)$ & 0.15 & $1.65(1.04-2.61)$ & 0.03 & N/A & N/A & $1.68(1.08-2.62)$ & $0.02^{h}$ \\
\hline
\end{tabular}

EFS Event-free survival; OS Overall survival; HR Hazard ratio; 95\% Cl 95\% Confidence interval; SNV Single nucleotide variant; N/A Not applicable. Component 3: encompasses high levels of NK cells (CD57+), low levels of IL17A and low Ki-67. Component 4: encompasses high Ki-67 index and high counts of CD68+ and CD163+ macrophages. $\left(^{*}\right)$ Adjustement for B-symptoms and the MIPI index (EFS); adjustement for B-symptoms and bone marrow infiltration (OS).$^{a} p($ bootstrap) $=$ $0.02,{ }^{\mathrm{b}} p$ (bootstrap) $=0.12,{ }^{\mathrm{C}} p$ (bootstrap) $=0.004,{ }^{\mathrm{d}} p$ (bootstrap) $=0.12,{ }^{\mathrm{e}} p$ (bootstrap) $=0.004,{ }^{\mathrm{f}} p$ (bootstrap) $=0.03,{ }^{9} p$ (bootstrap) $=0.11,{ }^{\mathrm{h}} p($ bootstrap $)=0.04$

or protein expression), and also due to the lack of a standardized cut-off for the immunohistochemical expression of SOX11 [63].

The limited sample size represents a drawback of this study. Furthermore, the two institutions involved in our study present different sociodemographical profiles that might influence response to therapy [64]. In addition, we were unable to assess TP53 mutational status, which is a well-known prognostic factor in MCL [65]. Therefore, we recognize the need of independent studies to validate 
our findings. However, the genotyping of SNVs in immune response genes, as well as the use of PCA in TME subpopulations, enabled a novel and more integrative approach to address the TME in MCL. Also, our survival analyses were performed only in patients that received anti-CD20; hence, our findings present translational relevance. Finally, the majority of the IHC markers were analyzed quantitatively and automatically, minimizing the risk of bias and poor reproducibility of manual scoring in lymphoma studies [66].

\section{Conclusions}

This is the first study to provide a broader approach of the TME in MCL, by evaluating both the TME immune cell composition in biopsies and SNVs within immuneresponse genes. Our study supports the associations of tumor FOXP3/CD3 ratios, IL17A and IL2 with outcome in the rituximab era. We also demonstrate, in the same cohort, the prognostic roles of TGFBR2 rs3087465, IL2 rs2069762 and the CC haplotype of IL10. The distinct approach presented herein might contribute to novel insights in the biology of MCL, and in future studies considering new therapeutic options in this lymphoma.

\section{Supplementary Information}

The online version contains supplementary material available at https://doi. org/10.1186/s12885-021-07891-9.

Additional file 1: Supplementary Table 1. Primary antibodies used for immunohistochemistry in this study.

Additional file 2: Supplementary Table 2. Clinicopathological features of the mantle cell lymphoma patients in this study.

Additional file 3: Supplementary Table 3. Cellular microenvironment composition and clinicopathological features of mantle cell lymphoma.

Additional file 4: Supplementary Table 4. Intratumoral expression of cytokines and clinicopathological features of mantle cell lymphoma.

Additional file 5: Supplementary Table 5. SOX11 expression and clinicopathological features in mantle cell lymphoma.

Additional file 6: Supplementary Table 6. Hardy-Weinberg equilibrium testing for all the SNVs assessed in this study.

Additional file 7: Supplementary Table 7. Frequencies of haplotypes in IL10 and IL12A in mantle cell lymphoma patients.

Additional file 8: Supplementary Table 8. Univariate Cox regression for clinicopathological features influencing survival of mantle cell lymphoma patients.

Additional file 9: Supplementary Table 9. Principal component analysis of the immunohistochemical variables in mantle cell lymphoma.

Additional file 10: Supplementary Fig. 1. Representative

photomicrographs of tumor-infiltrating lymphocytes in mantle cell lymphoma. (A) CD3, (B) CD4, (C) CD8, (D) CD57, (E) FOXP3, (F) PD1, (G) Granzyme B, (H) Perforin. Each letter is sub-labeled as "1", "2" and "3", representing, respectively, cases with weak, intermediate and strong positivity. All images were obtained at a 200x magnification.

Additional file 11: Supplementary Fig. 2. Representative photomicrographs of macrophages, iNOS staining and the proliferative index in mantle cell lymphoma. (A) CD68, (B) CD163, (C) iNOS, (D) Ki67. Each letter is sub-labeled as "1", "2" and " 3 ", representing, respectively, cases with weak, intermediate and strong positivity. All images were obtained at a 200x magnification.
Additional file 12: Supplementary Fig. 3. Representative photomicrographs of cytokines' stainings in mantle cell lymphoma. (A) IL12A, (B) IL2, (C) IL10, (D) TGFß, (E) TGFBR1, (F) TGFBR2, (G) IL17A, (H) IL17F. Each letter is sub-labeled as "1", "2" and "3", representing, respectively, cases with weak, intermediate and strong positivity. The exception is for TGFBR2, in which no convincing positivity was observed; therefore, F1, F2 and F3 represent negative cases. All images were obtained at a 200x magnification.

Additional file 13: Supplementary Fig. 4. Representative photomicrographs of SOX11 assessment in mantle cell lymphoma. (A) SOX $11^{\text {high }}$ case. (B) SOX $11^{\text {low }}$ case.

Additional file 14: Supplementary Fig. 5. Tumor microenvironment markers $(\mathbf{A}-\mathbf{R})$ and proliferation index $(\mathbf{S})$ in SOX $11^{\text {high }}$ and SOX $11^{\text {low }}$ mantle cell lymphoma cases. Horizontal lines represent the median levels, and the whiskers show interquartile ranges.

Additional file 15: Supplementary Fig. 6. Linkage disequilibrium (LD) plots in mantle cell lymphoma patients for (A) IL12A and (B) /L10 genes. In each square, the LD is measured between groups of single nucleotide variants. Higher values of LD (expressed as D') are shown in red squares.

\section{Abbreviations}

95\%Cl: 95\% Confidence interval; D': Linkage disequilibrium coefficient; EFS: Event-free survival; FFPE: Formalin-fixed, paraffin embedded; HWE: Hardy-weinberg equilibrium; IHC: Immunohistochemical; LD: Linkage disequilibrium; MCL: Mantle cell lymphoma; MIPI: Mantle cell lymphoma international prognostic index; NHL: Non-hodgkin lymphoma; OR: Odds ratio; OS: Overall survival; PCA: Principal component analysis; SNVs: Single nucleotide variants; TMA: Tissue microarray; TME: Tumor microenvironment; WHO: World health Organization

\section{Acknowledgements}

We are acknowledged to Érika Nascimento, Karina Ramos and Bruna Murbach for the help regarding the collection of patients' blood samples. We also thank Adilson Piaza for the help with the figure plates.

\section{Authors' contributions}

GRAM: designed the project, performed experiments, analyzed the data and wrote the manuscript. AF: analyzed the data and wrote the manuscript. RMR: performed experiments, analyzed the data and wrote the manuscript. GJ: analyzed the data and wrote the manuscript. MTD: collected and analyzed the data. SN: performed experiments and wrote the manuscript. VL: analyzed the data and wrote the manuscript. GWBC: analyzed the data and wrote the manuscript. CAS: analyzed the data and wrote the manuscript. FAS: analyzed the data and wrote the manuscript. CSPL: analyzed the data and wrote the manuscript. JV: designed the project, analyzed the data and wrote the manuscript. All the authors have read and approved the final version of the manuscript.

\section{Funding}

This study was supported by Fundação de Amparo à Pesquisa de São Paulo (FAPESP) (grant number 2014/09854-5) and Coordenação de Aperfeiçoamento de Pessoal de Nível Superior (CAPES) (grant number 62/ 2014).

The content of this article is of sole responsibility of the authors. The funding agencies had no roles in the study conception, data collection, analysis or manuscript preparation.

Availability of data and materials

The datasets used during the current study are available from the corresponding author on reasonable request.

Ethics approval and consent to participate

The study was approved by the Ethics Committees of both institutions (CAAE number: 32177014.3.0000.5404), and all procedures were carried out according to the Declaration of Helsinki.

Written informed consent was obtained from patients before inclusion in the study. 


\section{Consent for publication}

Not applicable.

\section{Competing interests}

The authors have no conflict of interest to disclose.

\section{Author details}

'Department of Pathology, Faculty of Medical Sciences, University of Campinas, Distrito de Barão Geraldo, Campinas, SP, Brazil. ${ }^{2}$ Department of Internal Medicine, Faculty of Medical Sciences, University of Campinas, Campinas, SP, Brazil. ${ }^{3}$ Molecular Gynecology Laboratory, Department of Gynecology, Federal University of São Paulo, São Paulo, Brazil. ${ }^{4}$ Laboratory of Cancer Genetics, Faculty of Medical Sciences, University of Campinas, Campinas, SP, Brazil. ${ }^{5}$ Hematology and Hemotherapy Center, University of Campinas, Campinas, Brazil. Instituto Adolfo Lutz, Secretaria de Estado da Saúde, São Paulo, SP, Brazil. ${ }^{7}$ Department of Medical Oncology, A C Camargo Cancer Center, São Paulo, Brazil. ${ }^{8}$ Department of Clinical and Experimental Oncology, Federal University of São Paulo, São Paulo, SP, Brazil. ' Rede D'Or Hospitals Network - Pathology Division, São Paulo, SP, Brazil. ${ }^{10}$ Laboratory of Investigative and Molecular Pathology (LIP), CIPED, Faculty of Medical Sciences, University of Campinas, Campinas, SP, Brazil.

Received: 18 May 2020 Accepted: 8 February 2021

Published online: 01 March 2021

\section{References}

1. Jain P, Wang M. Mantle cell lymphoma: 2019 update on the diagnosis, pathogenesis, prognostication, and management. Am J Hematol. 2019;94(6): 710-25.

2. Hoster E, Dreyling M, Klapper W, Gisselbrecht C, van Hoof A, Kluin-Nelemans $\mathrm{HC}$, et al. A new prognostic index (MIPI) for patients with advanced-stage mantle cell lymphoma. Blood. 2008;111(2):558-65.

3. Saba NS, Liu D, Herman SE, Underbayev C, Tian X, Behrend D, et al. Pathogenic role of B-cell receptor signaling and canonical NF-KB activation in mantle cell lymphoma. Blood. 2016;128(1):82-92

4. Malarikova D, Berkova A, Obr A, Blahovcova P, Svaton M, Forsterova K, et al. Concurrent TP53 and CDKN2A gene aberrations in newly diagnosed mantle cell lymphoma correlate with Chemoresistance and call for innovative upfront therapy. Cancers (Basel). 2020;12(8):2120.

5. Scott DW, Gascoyne RD. The tumour microenvironment in B cell lymphomas. Nat Rev Cancer. 2014;14(8):517-34.

6. Inamdar AA, Goy A, Ayoub NM, Attia C, Oton L, Taruvai V, et al. Mantle cell lymphoma in the era of precision medicine-diagnosis, biomarkers and therapeutic agents. Oncotarget. 2016;7(30):48692-31.

7. Koh YW, Shin SJ, Park C, Yoon DH, Suh C. Absolute monocyte count predicts overall survival in mantle cell lymphomas: correlation with tumourassociated macrophages. Hematol Oncol. 2014;32(4):178-86.

8. Nygren L, Wasik AM, Baumgartner-Wennerholm S, Jeppsson-Ahlberg $\AA$, Klimkowska M, Andersson P, et al. T-cell levels are prognostic in mantle cell lymphoma. Clin Cancer Res. 2014;20(23):6096-104.

9. Hou W, Wei P, Xie J, Zheng Y, Zhang Y, Zhou X. The degree of overlap between the follicular dendritic cell meshwork and tumor cells in mantle cell lymphoma is associated with prognosis. Pathol Res Pract. 2018;214(4): 513-20

10. Hofmann SR, Ettinger R, Zhou YJ, Gadina M, Lipsky P, Siegel R, et al. Cytokines and their role in lymphoid development, differentiation and homeostasis. Curr Opin Allergy Clin Immunol. 2002;2(6):495-506.

11. Zhang L, Yang J, Qian J, Li H, Romaguera JE, Kwak LW, et al. Role of the microenvironment in mantle cell lymphoma: IL-6 is an important survival factor for the tumor cells. Blood. 2012;120(18):3783-92.

12. Castillo R, Mascarenhas J, Telford W, Chadburn A, Friedman SM, Schattner EJ. Proliferative response of mantle cell lymphoma cells stimulated by CD40 ligation and IL-4. Leukemia. 2000;14(2):292-8.

13. Papin A, Tessoulin B, Bellanger C, Moreau A, Le Bris $Y$, Maisonneuve $H$, et al. CSF1R and BTK inhibitions as novel strategies to disrupt the dialog between mantle cell lymphoma and macrophages. Leukemia. 2019;33:2442-53.

14. Rothman N, Skibola CF, Wang SS, Morgan G, Lan Q, Smith MT, et al. Genetic variation in TNF and IL10 and risk of non-Hodgkin lymphoma: a report from the InterLymph consortium. Lancet Oncol. 2006;7(1):27-38.
15. Cerhan JR, Wang S, Maurer MJ, Ansell SM, Geyer SM, Cozen W, et al. Prognostic significance of host immune gene polymorphisms in follicular lymphoma survival. Blood. 2007;109(12):5439-46.

16. Chen Y, Zheng T, Lan Q, Foss F, Kim C, Chen X, et al. Cytokine polymorphisms in Th1/Th2 pathway genes, body mass index, and risk of non-Hodgkin Iymphoma. Blood. 2011;117:585-90.

17. Lech-Maranda E, Baseggio L, Charlot C, Rigal D, Berger F, Jamroziak K, et al. Genetic polymorphisms in the proximal IL-10 promoter and susceptibility to non-Hodgkin lymphoma. Leuk Lymphoma. 2007;48(11):2235-8.

18. Jorgensen TJ, Ruczinski I, Kessing B, Smith MW, Shugart YY, Alberg AJ. Hypothesis-driven candidate gene association studies: practical design and analytical considerations. Am J Epidemiol. 2009;170(8):986-93.

19. Medina DJ, Goodell L, Glod J, Gélinas C, Rabson AB, Strair RK. Mesenchymal stromal cells protect mantle cell lymphoma cells from spontaneous and drug-induced apoptosis through secretion of B-cell activating factor and activation of the canonical and non-canonical nuclear factor KB pathways. Haematologica. 2012;97(8):1255-63.

20. Swerdlow SH, Campo E, Pileri SA, Harris NL, Stein H, Siebert R. The 2016 revision of the World Health Organization classification of lymphoid neoplasms. Blood. 2016;127(20):2375-90.

21. Kueberuwa G, Kalaitsidou M, Cheadle E, Hawkins RE. Gilham DE.CD19 CAR T cells expressing IL-12 eradicate lymphoma in fully Lymphoreplete mice through induction of host immunity. Mol Ther Oncolytics. 2017;8:41-51.

22. Yang ZZ, Grote DM, Ziesmer SC, Niki T, Hirashima M, Novak AJ, et al. IL-12 upregulates TIM-3 expression and induces T cell exhaustion in patients with follicular B cell non-Hodgkin lymphoma. J Clin Invest. 2012;122:1271-82.

23. Butterbach K, Beckmann L, de Sanjosé S, Benavente Y, Becker N, Foretova L, et al. Association of JAK-STAT pathway related genes with lymphoma risk: results of a European case-control study (EpiLymph). Br J Haematol. 2011; 153:318-33.

24. Chang JS, Wiemels JL, Chokkalingam AP, Metayer C, Barcellos LF, Hansen $\mathrm{HM}$, et al. Genetic polymorphisms in adaptive immunity genes and childhood acute lymphoblastic leukemia. Cancer Epidemiol Biomark Prev. 2010;19:2152-63.

25. Lan Q, Wang SS, Menashe I, Armstrong B, Zhang Y, Hartge P, et al. Genetic variation in Th1/Th2 pathway genes and risk of non-Hodgkin lymphoma: a pooled analysis of three population-based case-control studies. $\mathrm{Br} J$ Haematol. 2011;15:341-50.

26. Börschel N, Schwöppe C, Zerbst C, Angenendt L, Kessler T, Klapper W, et al. Potentiating the activity of rituximab against mantle cell lymphoma in mice by targeting interleukin-2 to the neovasculature. Leuk Res. 2015;39(7):73948.

27. Fichna M, Zurawek M, Fichna P, Ziółkowska-Suchanek I, Januszkiewicz D, Nowak J. Polymorphic variant at the IL2 region is associated with type 1 diabetes and may affect serum levels of interleukin-2. Mol Biol Rep. 2013; 40(12):6957-63.

28. Visser HP, Tewis $M$, Willemze $R$, Kluin-Nelemans JC. Mantle cell lymphoma proliferates upon IL-10 in the CD40 system. Leukemia. 2000;14(8):1483-9.

29. Assis S, Marques CR, Silva TM, Costa RS, Alcantara-Neves NM, Barreto ML, et al. IL10 single nucleotide polymorphisms are related to upregulation of constitutive IL-10 production and susceptibility to helicobacter pylori infection. Helicobacter. 2014;19:168-73.

30. Lowe PR, Galley HF, Abdel-Fattah A, Webster NR. Influence of interleukin-10 polymorphisms on interleukin-10 expression and survival in critically ill patients. Crit Care Med. 2003:31:34-8.

31. Gibson AW, Edberg JC, Wu J, Westendorp RG, Huizinga TW, Kimberly RP. Novel single nucleotide polymorphisms in the distal IL-10 promoter affect IL-10 production and enhance the risk of systemic lupus erythematosus. J Immunol. 2001:166:3915-22.

32. Rizzatti EG, Falcão RP, Panepucci RA, Proto-Siqueira R, Anselmo-Lima WT, Okamoto OK, et al. Gene expression profiling of mantle cell lymphoma cells reveals aberrant expression of genes from the PI3K-AKT, WNT and TGF $\beta$ signalling pathways. Br J Haematol. 2005;130(4):516-26.

33. lerodiakonou D, Postma DS, Koppelman GH, Gerritsen J, ten Hacken NH, Timens $W$, et al. TGF- $\beta 1$ polymorphisms and asthma severity, airway inflammation, and remodeling. J Allergy Clin Immunol. 2013;131:582-5.

34. Grainger DJ, Heathcote K, Chiano M, Snieder H, Kemp PR, Metcalfe JC, et al. Genetic control of the circulating concentration of transforming growth factor type $\beta 1$. Hum Mol Genet. 1999;8:93-7.

35. Awad MR, El-Gamel A, Hasleton P, Turner DM, Sinnott PJ, Hutchinson IV. Genotypic variation in the transforming growth factor- $\beta 1$ gene: association 
with transforming growth factor- $\beta 1$ production, fibrotic lung disease, and graft fibrosis after lung transplantation. Transplantation. 1998;66:1014-20.

36. Nicoloso MS, Sun H, Spizzo R, Kim H, Wickramasinghe P, Shimizu M, et al. Single-nucleotide polymorphisms inside microRNA target sites influence tumor susceptibility. Cancer Res. 2010;70:2789-98.

37. Seijo ER, Song $H$, Lynch MA, Jennings $R$, Qong $X$, Lazaridis $E$, et al. Identification of genetic alterations in the TGFbeta type II receptor gene promoter. Mutat Res. 2001;483:19-26.

38. Lu T, Yu S, Liu Y, Yin C, Ye J, Liu Z, et al. Aberrant circulating Th17 cells in patients with B-cell non-Hodgkin's lymphoma. PLoS One. 2016;11(1): e0148044.

39. Montico B, Lapenta C, Ravo M, Martorelli D, Muraro E, Zeng B, et al. Exploiting a new strategy to induce immunogenic cell death to improve dendritic cell-based vaccines for lymphoma immunotherapy. Oncoimmunology. 2017;6(11):e1356964.

40. Wang $L$, Jiang $Y$, Zhang $Y$, Wang $Y$, Huang $S$, Wang $Z$, et al. Association analysis of IL-17A and IL-17F polymorphisms in Chinese Han women with breast cancer. PLoS One. 2012;7:e34400.

41. Krejsgaard T, Litvinov IV, Wang Y, Xia L, Willerslev-Olsen A, Koralov SB, et al. Elucidating the role of interleukin-17F in cutaneous T-cell lymphoma. Blood. 2013;122:943-50

42. Kawaguchi M, Takahashi D, Hizawa N, Suzuki S, Matsukura S, Kokubu F, et al. IL-17F sequence variant (His161 Arg) is associated with protection against asthma and antagonizes wild-type IL-17F activity. J Allergy Clin Immunol. 2006;117:795-801.

43. Byers RJ, Currie T, Tholouli E, Rodig SJ, Kutok JL. MSI2 protein expression predicts unfavorable outcome in acute myeloid leukemia. Blood. 2011; 118(10):2857-67.

44. Lee W, Shin E, Kim BH, Kim H. Diagnostic accuracy of SOX11 immunohistochemistry in mantle cell lymphoma: a meta-analysis. PLoS One. 2019;4(11):e0225096.

45. Croci GA, Hoster E, Beà S, Clot G, Enjuanes A, Scott DW, et al. Reproducibility of histologic prognostic parameters for mantle cell lymphoma: cytology, Ki67, p53 and SOX11. Virchows Arch. 2020;477(2):259-67.

46. Lever J, Krzywinski M, Altman N. Principal component analysis. Nat Methods. 2017:14:641-2

47. Fowler NH, Cheah CY, Gascoyne RD, Gribben J, Neelapu SS, Ghia P, et al. Role of the tumor microenvironment in mature B-cell lymphoid malignancies. Haematologica. 2016;101(5):531-40.

48. Domenech J, Roingeard F, Hérault O, Truglio D, Desbois I, Colombat P, et al. Changes in the functional capacity of marrow stromal cells after autologous bone marrow transplantation. Leuk Lymphoma. 1998;29(5-6):533-46.

49. Ramakrishnan A, Torok-Storb BJ. The role of the marrow microenvironment in hematopoietic stem cell transplantation. Cell Ther Transplant. 2010:2(7):7-12.

50. Jayappa KD, Portell CA, Gordon VL, Capaldo BJ, Bekiranov S, Axelrod MJ, et al. Microenvironmental agonists generate de novo phenotypic resistance to combined ibrutinib plus venetoclax in CLL and MCL. Blood Adv. 2017; 1(14):933-46

51. Chiron D, Bellanger C, Papin A, Tessoulin B, Dousset C, Maiga S, et al. Rational targeted therapies to overcome microenvironment-dependent expansion of mantle cell lymphoma. Blood. 2016;128(24):2808-18.

52. Farinha P, Al-Tourah A, Gill K, Klasa R, Connors JM, Gascoyne RD. The architectural pattern of FOXP3-positive T cells in follicular lymphoma is an independent predictor of survival and histologic transformation. Blood. 2010;115(2):289-95.

53. Cochaud S, Giustiniani J, Thomas C, Laprevotte E, Garbar C, Savoye AM, et al. IL-17A is produced by breast cancer TILs and promotes chemoresistance and proliferation through ERK1/2. Sci Rep. 2013;3:3456.

54. Ferretti E, Di Carlo E, Ognio E, Guarnotta C, Bertoni F, Corcione A, et al. Interleukin-17A promotes the growth of human germinal center derived non-Hodgkin B cell lymphoma. Oncolmmunology. 2015;4(10):e1030560.

55. Voo KS, Wang YH, Santori FR, Boggiano C, Wang YH, Arima K, et al. Identification of IL-17-producing FOXP3 + regulatory T cells in humans. Proc Natl Acad Sci U S A. 2009;106(12):4793-8.

56. Hohaus S, Giachelia M, Di Febo A, Martini M, Massini G, Vannata B, et al. Polymorphism in cytokine genes as prognostic markers in Hodgkin's lymphoma. Ann Oncol. 2007;18(8):1376-81.

57. Kim MK, Yoon KA, Park EY, Joo J, Lee EY, Eom HS, et al. Interleukin-10 polymorphisms in association with prognosis in patients with with B-cell lymphoma treated by R-CHOP. Genomics Inform. 2016;14(4):205-10.
58. Matesanz F, Fedetz M, Leyva L, Delgado C, Fernández O, Alcina A. Effects of the multiple sclerosis associated -330 promoter polymorphism in IL2 allelic expression. J Neuroimmunol. 2004;148(1-2):212-7.

59. Mozos A, Royo C, Hartmann E, De Jong D, Baró C, Valera A, et al. SOX11 expression is highly specific for mantle cell lymphoma and identifies the cyclin D1-negative subtype. Haematologica. 2009:94(11):1555-62.

60. Balsas P, Palomero J, Eguileor Al, Rodríguez ML, Vegliante MC, Planas-Rigol E, et al. SOX11 promotes tumor protective microenvironment interactions through CXCR4 and FAK regulation in mantle cell lymphoma. Blood. 130(4):501-13.

61. Fernàndez V, Salamero O, Espinet B, Solé F, Royo C, Navarro A, et al. Genomic and gene expression profiling defines indolent forms of mantle cell lymphoma. Cancer Res. 2010;70(4):1408-18.

62. Nygren L, Baumgartner Wennerholm S, Klimkowska M, Christensson B Kimby E, Sander B. Prognostic role of SOX11 in a population-based cohort of mantle cell lymphoma. Blood. 2012;119(18):4215-23.

63. Lee W, Shin E, Kim BH, Kim H. Inconsistency associated with SOX11 immunohistochemistry in mantle cell lymphoma: a meta-analysis. J Hematop. 2019;12:109-19.

64. Assis-Mendonça GR, Crepaldi AH, Delamain MT, Moreira AH, Costa FD, Lima VCC, et al. Characteristics of follicular and mantle cell lymphoma in Brazil: prognostic impact of clinical parameters and treatment conditions in two hospitals. Hematol Transfus Cell Ther. 2018:40(4):343-53.

65. Halldórsdóttir AM, Lundin A, Murray F, Mansouri L, Knuutila S, Sundström C, et al. Impact of TP53 mutation and 17p deletion in mantle cell lymphoma. Leukemia. 2011;25(12):1904-8.

66. Sander B, de Jong D, Rosenwald A, Xie W, Balaqué O, Calaminici M, et al. The reliability of immunohistochemical analysis of the tumor microenvironment in follicular lymphoma: a validation study from the Lunenburg lymphoma biomarker consortium. Haematologica. 2014;99(4):715-25.

\section{Publisher's Note}

Springer Nature remains neutral with regard to jurisdictional claims in published maps and institutional affiliations.

\section{Ready to submit your research? Choose BMC and benefit from:}

- fast, convenient online submission

- thorough peer review by experienced researchers in your field

- rapid publication on acceptance

- support for research data, including large and complex data types

- gold Open Access which fosters wider collaboration and increased citations

- maximum visibility for your research: over $100 \mathrm{M}$ website views per year

At $\mathrm{BMC}$, research is always in progress.

Learn more biomedcentral.com/submissions 